\title{
Conceptual Model for Smart Cities: Irrigation and Highway Lamps using IoT
}

\author{
Vijender Kumar Solanki, M.Venkatesan, Somesh Katiyar \\ Research Scholar, Anna University, Chennai, India
}

\begin{abstract}
Keeping in mind the need to preserve energy as well as utilize the available at its best the need was felt to develop a module that would be able to sort out the problem where resources such as water and electricity were wasted, in urban as well as rural area. Resource (electricity) was wasted as beside the point operation of Highway \& High Mast Lamp; while wastage of water followed by improper trends and methodologies imparted for watering of city park, road side plantation and highway plantation. Thus as per Energy survey statistics of a City (Lucknow, India) it was found that major portion of resources (water and electricity) were being wasted due to negligent activities of officials who were in charge of resource management. So to facilitate energy saving trends and to completely modernize it to autonomous system, module below is proposed which incorporates modern technological peripheral and has its base ingrained in IoT (Internet of Things) which when put into consideration would result in large scale resource and energy saving. This developed module incorporates the peripherals such as Arduino, Texas Instruments ultra low power kits etc. in accordance with software technology including Lab View which help to monitor as well as control the various operation from the base station, located far away from the site. Lab View Interface interacts with all the module located at various city parks, subways and highway lighting modules. Later below in several section a detailed pattern and application frame has been put up.
\end{abstract}

Keywords - Smart City, Arduino, Lab-View, Automatic Irrigation System, (Highway lamp / High Mast Lighting) Operation and Control.

\section{INTRODUCTION}

s per the growing rate of population with spontaneous consumption A of resources, creates in the need for the managing the available resources at its best. So a need was felt to manage the outflow of the two major resources i.e. water and electricity and to formulate out, that's how it can be protected from getting wasted and could be utilized at its best. [1]

As during the survey study, it was found that (Lucknow, in India) the practices were manual and a major portion of resources was wasted due to slothful and unconcerned behavior leading to plant death and unwanted operation of the lights.

So using modern technology, and statistical, survey based study it was found that that major portion of the resources (water and Electricity) could be managed out and preserved by managing their controlled flow in an allocated area/city/state/territory with channelized Irrigation system and employing modern means for control of Highway lamps and High Mast Lighting. [2,3]

- Primarily, this module would be capable to help, rule out the problem faced with irrigation process, which was carried out manually, and improper trends were practiced which were either resulting in resource (water) wastage or when not followed properly resulting in plant dying out indirectly unfavorable habitat.

- Secondarily the module helps in controlling the Lamps of Various Highways based on collection of data from weather forecast report (such as visibility, mist, fog etc.) and toll plaza as per the traffic density so that accordingly the lights/lamp/ high mast lamp could be operated.

\section{Technology Adopted}

The developed module, thus incorporates the solution for both of the issues:

I.) Advanced Irrigation System for Parks and Road Side Plantation: It includes grouping together of various peripherals together using IoT which help in:

- Data accusation (such as: Status of fountain Running/Idle position; Water Level in the Tank; Soil Moisture Content: rated b/w 0 to 100) $[4,5,6]$

- Remote Operation Enables to control the various operations such as Operation of Lights, Operation of Fountain Pump, Operation of Sprinklers of City Parks and Road Side Plantation.

II.) Advanced Highway and High Mast Lighting System: Provides automatic control of the lights of the Highway and High Mast Light based on the:

- Weather Forecast (Visibility, Fog etc.): As it was found that during bad weather less visibility, fog affected condition it is necessary to operate all the lights at its full.

- Traffic Density: Data from the Toll Plaza has to be collected so accordingly the operation of Lamps if necessary could be operated in the available modes. (Alternate Mode, Full Mode operations)

\section{Problem Formulation}

The module at base station includes the Lab-View platform installed PC enabling:

- Highway lamps to be controlled as per the requirement through remote access [7]

- Irrigation related functioning such as: Water Level in Tank, Operation of Sprinkler, and Operation of Fountain Lights can be achieved [8].

In the schematic figure below Fig. 1 represents the base station in continuous communication link with the discrete module i.e. Highway / High Mast Lamp and Irrigation module with on sites comm. through $30 \mathrm{ft}$ Rx Tx Weatherproof Communication Link Network (SPN2dp8 for $5 \mathrm{Km}$ radii Communication range with 0 obst.)

At center lies the base station where Lab view platform based Host PC is installed while on to left half depicts the Highway and high mast Lighting control module where Arduino set's connected to 

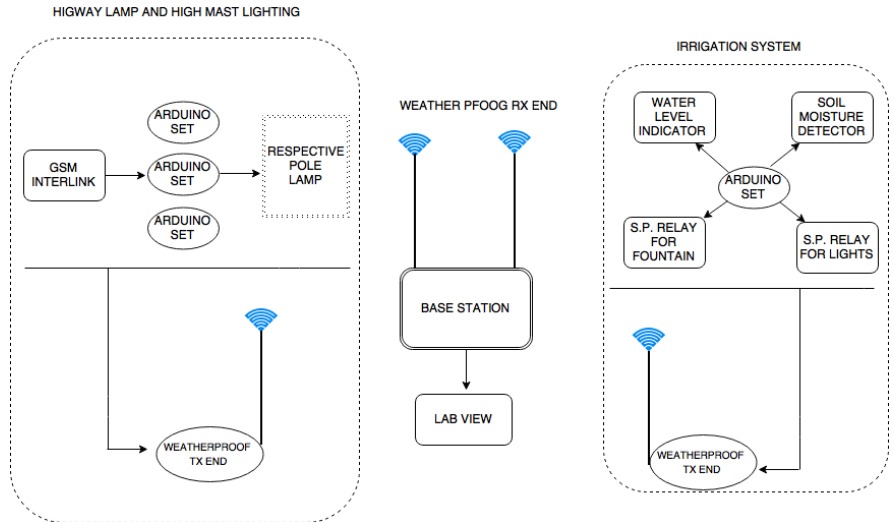

Fig. 1. Working Module describing the concept of interlink network and peripherals of Advanced Highway and Irrigation System in Smart City

sensor for feedback are inter-connected through GSM link via (SIM com900A module for Indian telecom) and giving resultant feed up to weatherproof TX. Whereas on to right-half irrigation module with sub-discrete peripheral such as Water level Indicator, Soil moisture detection, Fountain operator, and fountain light operator connected for data exchange to Arduino mega 2560 and then to weather proof TX end to base Rx end.

\section{Advanced Highway and High Mast Lighting}

Problem Observed: Over the course of time it was observed that much of the energy was wasted as these highly energy rated lamps remained to "ON" state, being in operation, although there was no requirement, this was the result of negligence of officials/engineers incharge of controlling the operation.

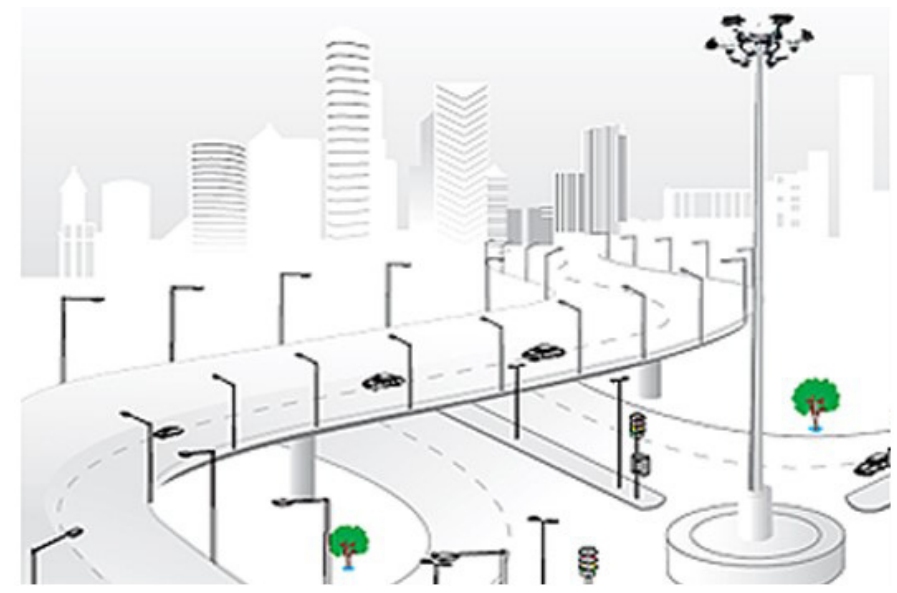

Fig 2. A layout of current employed system as per for installation of High Mast Lighting and Highway lamps.

Thus as a measure of substitute to existing system (as solution) module is proposed that is completely automatic and highly efficient. This would help to prevent the losses, will help in better saving and optimal utilization of resources. [9,10,11]. Fig. 2 depicts current trends of a city installed with manually controlled Highway and High Mast Lights. Fig3. Presents IOT based solution using Lab view as a running base platform to manage the lighting system of Highways as per the following aspect into consideration:

- User end Software Controlled

- Visibility on the road

- Traffic density on the road

In this at base station a trained operator or engineer controls the light as per stats and data from live footages as per the traffic density ratio.

- Autonomous via software control

In this mode data from servers of toll plaza and weather forecast are considered and as per initialized threshold value the respective light are operated, complete activity being autonomous.

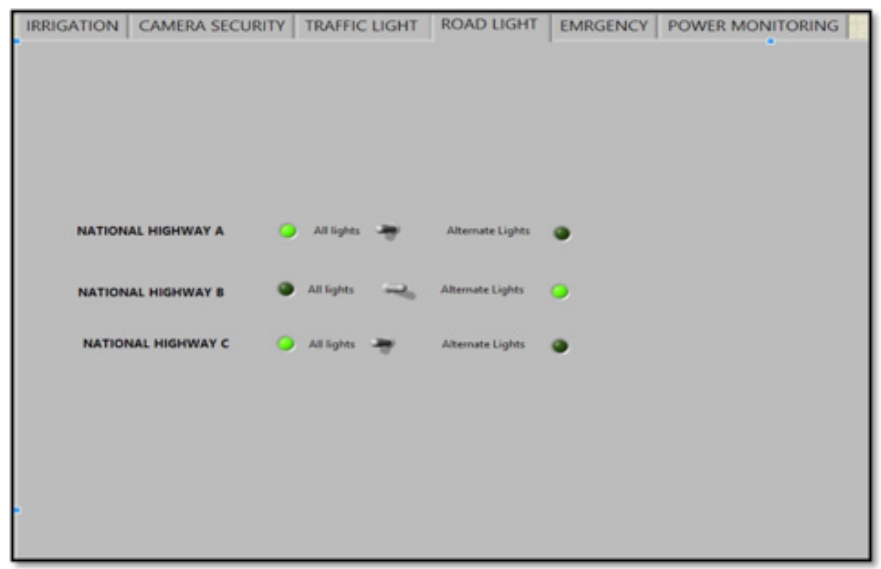

Fig 3. Lab View VI Module for Controlling of Highway Lamp's ( can be controlled Manually through switching from Base Station as per the data received from Toll Plaza, and weather forecast report) (simulation based result).

\section{Operational Framework}

Requirement:

- Data from the Toll Plaza $[12,13]$

Data from the toll plaza is collected through server based channels at the Smart City and Security base station, where a systematic study is carried out about the traffic density on that particular Highway.

- Data from weather Forecast[14]

Weather forecast data is required for the keeping in the record of the weather as well as the visibility, that depends on rain, fog, mist etc.

- Arduino Kit:

Build type: Arduino UNO

Purpose: Receive the signal form sensors such as Moisture detector or water level indicator and transfer the data to GSM module for transmission to Smart City baseStation $[15,16,17]$

Work Type: It performs both digital as well as analog collection of data and develop digital codes and results that can be manipulated and transferred or recorded.

- Weatherproof $300 \mathrm{ft}$. TX. Kit for video Link [18,19]

Purpose: Long range Video System, Birthing and Livestock Footage (transmission Type)

Work Type: (a.) Real time footage capture (b.) Digitalization (Encoding) for Easy Transmission

- Weatherproof $300 \mathrm{ft}$. RX. Kit for video Link [20]

Purpose: Long range Video System, Birthing and Livestock Footage (Receiving Type)

Work Type: (a.) Real time footage, receiving (b.) Decoding of receiving Data 


\section{IRRIGATION SySTEM}

In order proper maintain lush green plants / trees in smart city have to be watered regularly, i.e. watering of fields of city parks and road side plants. Earlier practices involved either water channeling or manual irrigation, thus when proper care is not undertaken or not properly practiced leading to plant death. Apart from this manually operating water pumps for tank filling and sprinkler operation led to water as well as electrical energy wastage as beyond the need operation. [21]

This IOT based module enables to maintain the well suited condition for the plants so that, they can grow at best to provide in shed and also maintain the natural beauty. $[22,23]$

The moisture content in the soil can easily be measured using the Soil Hygrometer Detection Module, which is buried in the soil and gives the continuous reading. As per the plant requirement the operation of sprinkler can be operated manually or automatically obtain the required results and maintain the best suitable condition for growth of plants. And for maintaining proper level of water in water tanks water level indicators are being employed to maintain the subsequent water for irrigation purpose. [24,25]

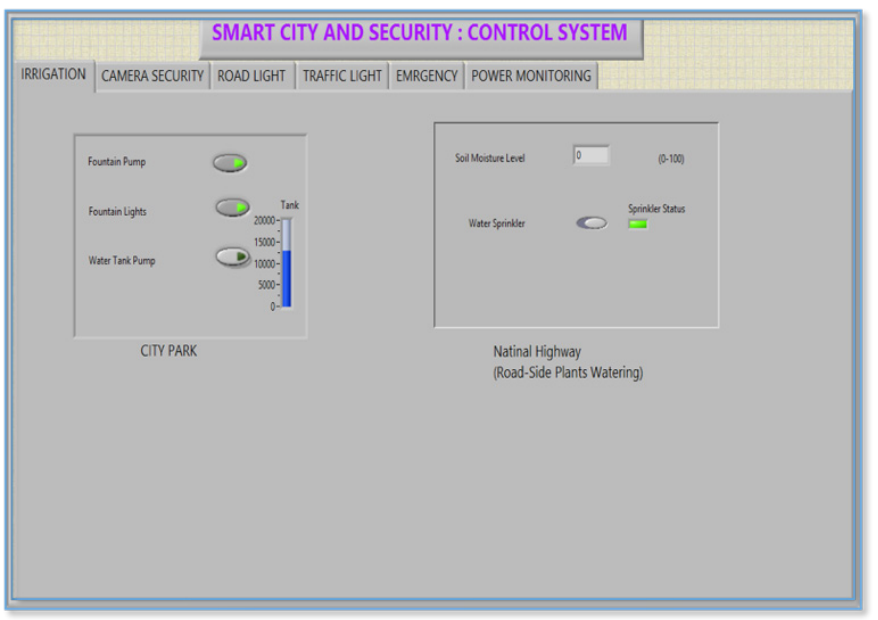

Fig 4:Lab View VI Module for Advanced Irrigation System help to control as well as for Data Accusation of Water Tank Level, Operate Sprinkler, Fountain and Fountain Lights.

Fig. 4 depicts the Lab View module for various condition such as:

- Control and status of water sprinkler

- Soil moisture level at time of sprinkler operation (rated 1\% - 100 $\%)$

- Control and status of water pump

- Control and status of fountain pump

- Control and status of fountain lights

- Amount of water level in heavy capacity water tank

VII. Operational Framework

Requirement:

- Soil Moisture Detector:

Build Type: PIC Atmel Based

Purpose: To collect the data about the moisture content of the soil

Work Type: The results are obtained in form of resistance, between two electrodes giving the conductivity lesser the moisture: more the resistance

more the moisture: more the conductivity

- Arduino Kit:

Build type: Arduino UNO

Purpose: Receive the signal form sensors such as Moisture detector or water level indicator and transfer the data to GSM module for transmission to Smart City base Station

Work Type: It performs both digital as well as analog collection of data and develop digital codes and results that can be manipulated and transferred or recorded.

Ñ Texas Instruments MSP430G2553:

Purpose: Ultra low power with booster pack plug in module, mainly for frequency decoding, serial interport, relay board power, segment display

\section{- GSM Kit: (Rx and Tx)}

Build Type: SIM 900 Module for Data TX and RX

Purpose: The digital data received form the Arduino has to be transmitted to base station of the Smart City and Security to operate the sprinkler located

- Water Level indicator:

Build Type: SD512 Resistive (Non Corrosive)

Purpose: Water level is also a resistive type basically modeled to carry out and note down the capacity of the water tank.

- Relay Single Pole:

Build Type: JQC3F 5 Pin SPDT

Purpose: Controlling and Switching of Fountain Lights and Sprinkler

Fig 5. Depicts the simulation based operation of various pump set with indicator repressing overflow state and power status. In case of detection of high signal value either at over flow or at moisture level beyond threshold operation the relay card in Fig 6. Carries out the necessary operation i.e. to bring back the pump to OFF state. In other words, the relay card can be regarded as main functioning unit for operation of heavy motors. Below is simulation based study carried out with single relay to drive up a single motor. While implementing this circuit in practical use repeated number of relay cards have to be connected to drive each motor for desired purpose.

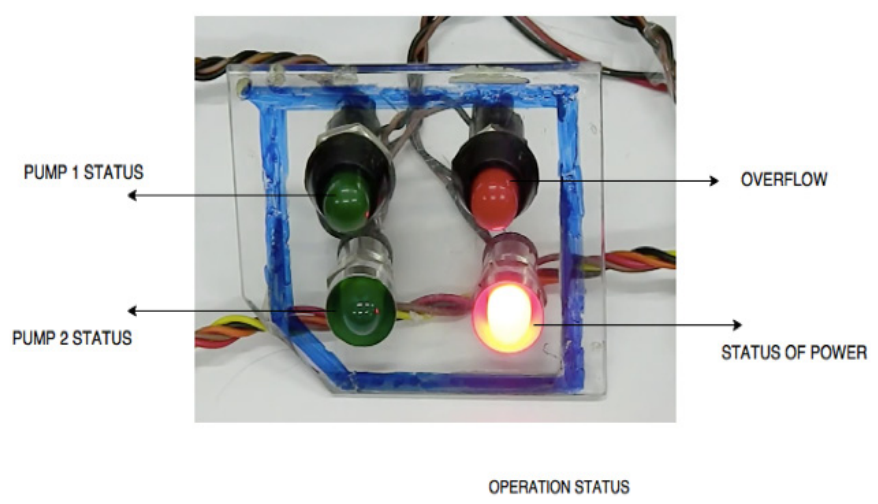

Fig 5:Operation Status display (Real Time) installed at operating end. 


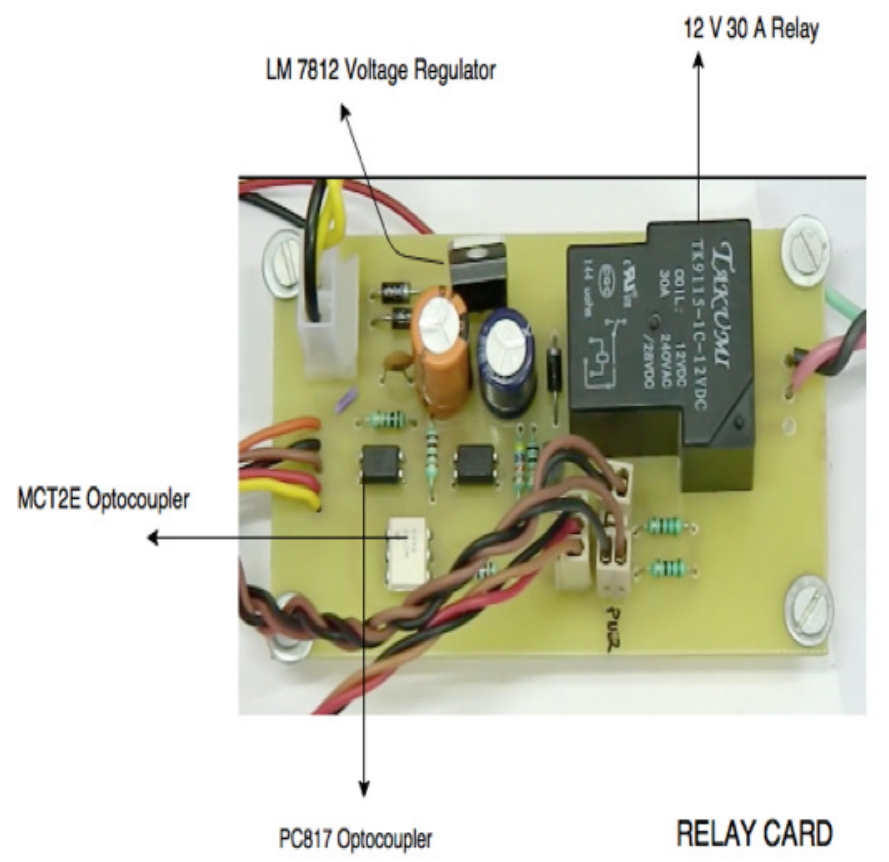

Fig. 6:Relay card for Driving Motor: for water pump set, and sprinkler operation.

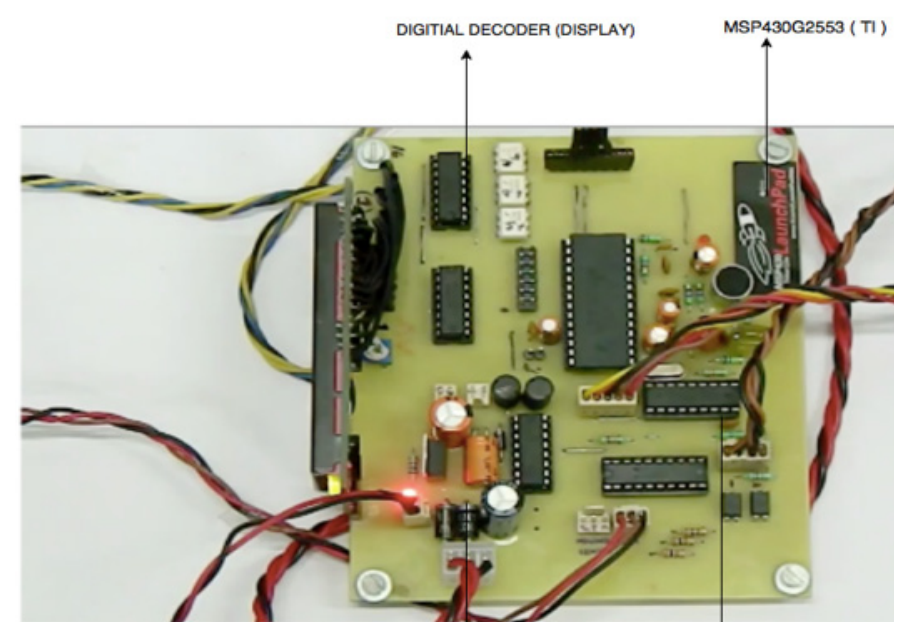

Fig. 7: Master Card driver for Serial channel interface, relay card driving and peripheral operation.

While the min processing units where received signals from base station are received is decoded at master card shown in Fig. 7 which carries out necessary calculation as well as decoding of received data and serves the signal to relay card for specific motor operation.

\section{FUTURE WORK}

The developed module has been tested on simulation and works well with android platform. But currently its pejorative to iOS platform due to intricacy involved. Apart from this future work is more focused toward maintaining the accuracy and precision for a particular task to be carried up. Such as detecting moisture in soil is limited because of limited analog pins in Arduino so future work would incorporate analogous sensor data collection and working on precision and accuracy.

The major achievement could be attained by modulating the signal frequency over a single band for high bit-rate data communication, using advanced data communication devices.

\section{Result AND Conclusion}

- After installation of the module to city better controllability of sprinkler's, tracking level of water and simultaneously operate the water pump could be successfully achieved which are being tested, and thus resources both water and electricity could be managed and saved unto a great extent.

- Apart from this major portion of electrical energy which was initially wasted as beyond the point operation of Highway lamps and High mast lamps would now be avoided and better safe and saving operation could be carried out.

- Data form both the sources are gathered up and studied both manually and technically and according to the comfort the lights can be operated.

- Table below depicts the study of operation of Highway lamps (Lab View VI software based simulation result) for Comparative study of the saving made after installation. The trends and values are as per weather condition (in Lucknow) $26.30: 27.10$ North latitude : : $80.30: 81.13$ East longitude (India). As per day pattern and natural light availability.

TABLE I STUDY OF OPERATION HIGHWAY LAMPS

\begin{tabular}{|c|c|c|c|}
\hline & $\begin{array}{c}\text { OLD } \\
\text { Installation }\end{array}$ & $\begin{array}{c}\text { Modern } \\
\text { Installation }\end{array}$ & Savings \\
\hline Jan & $13 \mathrm{Hrs.}$ & $9 \mathrm{Hrs}$. & $4 \mathrm{Hrs}$. \\
\hline Feb & $12.5 \mathrm{Hrs}$. & $8 \mathrm{Hrs}$. & $4.5 \mathrm{Hrs}$. \\
\hline May & $10 \mathrm{Hrs}$. & $7 \mathrm{Hrs}$. & $3 \mathrm{Hrs}$. \\
\hline July & $9 \mathrm{Hrs}$. & $7 \mathrm{Hrs}$. & $2 \mathrm{Hrs}$. \\
\hline Sep & $8 \mathrm{Hrs}$. & $7 \mathrm{Hrs}$. & $1 \mathrm{Hrs}$. \\
\hline Nov & $9 \mathrm{Hrs}$. & $8 \mathrm{Hrs}$. & $1 \mathrm{Hrs}$. \\
\hline
\end{tabular}

The graphical statics of the above Table 1 is Chart 1 which helps to comprehend it better.

Chart 1: Stats showing the difference if energy consumption or in words savings made after installation of the module, data to related chart form Table 1.

\section{= Modern Intallation =OId Installation}

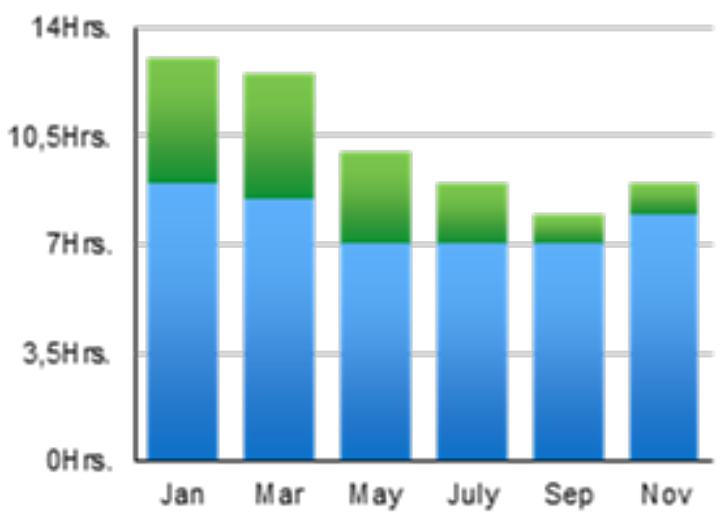

Table 2 here shows an outline of appliances installed, their wattage rating, and approx. consumption of Electric Power in a single day. 
TABLE II. OUTLINE OF APPLIANCES INSTALLED

\begin{tabular}{|c|c|c|c|c|}
\hline Appliance & $\begin{array}{c}\text { Wattage } \\
\operatorname{rating}(\mathrm{kW})\end{array}$ & $\begin{array}{c}\text { Installation } \\
\text { (No.) }\end{array}$ & $\begin{array}{l}\text { Hrs. of } \\
\text { Operation } \\
\text { (Hrs) }\end{array}$ & $\begin{array}{c}\text { Power } \\
\text { Consumption } \\
(\mathrm{kWh})\end{array}$ \\
\hline $\begin{array}{c}\text { Air } \\
\text { Conditioner }\end{array}$ & 3.3 & 1 & $\begin{array}{c}6 \\
* \text { Conditional }\end{array}$ & $\begin{array}{l}3.3 * 6 \\
=19.8\end{array}$ \\
\hline $\begin{array}{l}\text { Ceiling } \\
\text { Fan }\end{array}$ & 0.73 & 5 & $\begin{array}{c}8 \\
\text { *Conditional }\end{array}$ & $\begin{array}{c}0.73 * 5 * 8 \\
=17.2\end{array}$ \\
\hline $\begin{array}{l}\text { Florescent } \\
\text { Lamp }\end{array}$ & 0.4 & 7 & $\begin{array}{c}4 \\
* \text { Conditional) }\end{array}$ & $\begin{array}{l}0.4 * 28 \\
=11.2\end{array}$ \\
\hline Geyser & 1.2 & 1 & $\begin{array}{c}-/ \\
* * \text { Occasional }\end{array}$ & - - \\
\hline $\begin{array}{l}\text { Outdoor } \\
\text { Lamp }\end{array}$ & 0.80 & 2 & $\begin{array}{c}4 \\
* \text { Conditional }\end{array}$ & $\begin{array}{l}0.8 * 8 \\
=6.4\end{array}$ \\
\hline $\begin{array}{l}\text { Garden } \\
\text { Lamp }\end{array}$ & 0.6 & 8 & $\begin{array}{c}-/ \\
* * * \text { Optional }\end{array}$ & - - \\
\hline $\begin{array}{l}\text { Garden } \\
\text { Sprinkler }\end{array}$ & 0.43 & 2 & $\begin{array}{c}2 \\
* * * \text { Optional }\end{array}$ & $\begin{array}{l}0.43 * 4 \\
=1.72\end{array}$ \\
\hline $\begin{array}{l}\text { Desktop } \\
\text { Computer }\end{array}$ & 0.145 & 1 & $\begin{array}{c}8 \\
* \text { Conditional }\end{array}$ & $\begin{array}{c}0.145 * 8 \\
=1.16\end{array}$ \\
\hline Fridge & 0.433 & 1 & $\begin{array}{c}9 \\
\text { *variable }\end{array}$ & $\begin{array}{c}0.433 * 9 \\
=3.897\end{array}$ \\
\hline Total: & - & & & 61.377 Units \\
\hline
\end{tabular}

Hrs. of Operation:

*Conditional: Appliance operation may vary, example is just mend to illustrate

**Occasional: These appliances are not that frequent as others

***Optional: These appliances/equipment's are not commonly installed in every home

Table 2 help us to comprehend that the saving made from data of table 1 and help to drive loads of domestic utility.

Illustrative Example: Combining the data from Table 1 and Table 2 it can easily be comprehended that let say for a day in Jan per day saving made is of 4 Hrs. Now,

Taking case of $2 \mathrm{Km}$ road having 22 Road Lamps of $500 \mathrm{~W}$ (Model :Havells LHSH10050099) installed

So,

No. of Lamps * Wattage Rating * No. Hrs of Operation $=$ Power Consumption in Units

$$
N * W * H r=k W h r(\text { Units })
$$

$O_{l} 22 * 0.500 \mathrm{~W} * 13=143 \mathrm{kWh}$ \{old Installation $\left.O_{p}\right\}$

$M_{o} 22 * 0.500 W * 9=99 \mathrm{kWh} \quad\left\{\right.$ modern installation $\left.M_{o^{\prime}}\right\}$

$O_{l}-M_{o}=143-99=44 \mathrm{kWh}\{$ saving made $\}$

: Since in table 2 on an avg. a domestic appliance utilizes (61.377 62) units per day from which 44 units can be supplied from savings made and thus their remains only 18 units to be met.

Therefore, from above statics, savings made from operation Highway lamp and High mast lamp can be studied and compared to per day domestic utility to frame out savings. Thus if this system brought up and is employed it would definitely help to make enormous savings and serve out domestic users.
ACKNOWLEDGMENT

The authors are extremely grateful to the reviewers whose comments have led to significant improvement in the quality of the paper.

\section{REFERENCES}

[1] Vijender Kumar .Solanki, M. Venkatesan, S. Katiyar, Vijay B. Semwal, P. Dewan, N. Dey 2016, 'Advanced Automated Module for Smart and Secure City', Elsevier: Procedia Computer Science, Vol. 78, Page 367-374.

[2] A. Khattak, M. Pervez, Z. Jehad Sarkar, A. M. and Y. Lee, "Service Level Semantic Interoperability", 10th IEEE/IPSJ International Symposium On Applications And The Internet, Saint, pp. 387-390.

[3] P. Barnaghi, W. Wang, C. Henson and K. Taylor, "Semantics for the Internet of Things: Early Progress and Back to the Future", International Journal on Semantic Web and Information Systems, vol. 8, no. 1, 2012

[4] L. Atzori, A. Iera and G. Morabito, "The internet of things: A survey", Computer Networks, vol. 54, no. 15, pp. 2787-2805, 2010.

[5] M. Dohler, I. Vilajosana, X. Vilajosana and J. LLosa, Barcelona Smart Cities Congress 2011.

[6] G. Flouris, D. Plexousakis and G Antoniou, "A Classification of Ontology Change", The Poster Session of Semantic Web Applications and Perspectives (SWAP), 3rd Italian Semantic Web Workshop

[7] N. Bressan, L. Bazzaco, N. Bui, P. Casari, L. Vangelista and M. Zorzi, "The deployment of a Smart Monitoring System using Wireless Sensor and Actuator Networks", Proc. of IEEE Smart Grid Comm 2010.

[8] C. E. A. Mulligan and M. Olsson, "Architectural implications of smart city business models: an evolutionary perspective", IEEE Communications Magazine, vol. 51, no. 6, pp. 80-85, 2013.

[9] N. Walravens and P. Ballon, "Platform business models IoT-A consortium", Mission-IoT-A: Internet of Things Architecture.

[10] H. Schaffers, N. Komninos, M. Pallot, B. Trousse, M. Nilsson and A. Oliveira, "Smart Cities and the Future Internet: Towar ds Cooperation Frameworks for Open Innovation", The Future Internet, Lecture Notes in Computer Science, vol. 6656, pp. 431-446, 2011.

[11] D. Steinberg and S. Cheshire, "Zero Configuration Networking: The Definitive Guide", O'Relly Media, Inc., 2005.

[12] A. Narayanan and V. Shmatikov, "Robust De-anonymization of Large Sparse Datasats", 2008 IEEE Symposium on Security and Privacy ( $s p$ 2008). IEEE, pp. 111-125.

[13] Hussain M.J. Almohri, Danfeng (Daphne) Yao and Dennis Kafura, "Process Authentication For High System Assurance", Ieee Transactions On Dependable And Secure Computing, vol. 11, no. 2, 2014.

[14] Lin Gu, Deze Zeng, Peng Li and Song Guo, "Cost Minimization For Big Data Processing In Geo-Distributed Data Centers", 10 March 2014; Date Of Current Version 30 October 2014. Digital Object Identi_Er 10.1109/ Tetc.2014.2310456.

[15] A. Verma, L. Cherkasova and R. Campbell, "Aria: automatic resource inference and allocation for mapreduce environments", Proc. ACM ICAC.

[16] U. Kang, C. E. Tsourakakis and C. Faloutsos, "PEGASUS: mining petascale graphs", Knowledge and Infomation Systems, vol. 27, no. 2, 2011.

[17] Jeffrey Dean and Sanjay Ghemawat, "Mapreduce: Simpli_Ed Data Processing On Large Clusters", At To Appear In Osdi, 2004.

[18] Brian Hellig, Stephen Turner, Rich Collier and Long Zheng, "Beyond Map Reduce: The Next Generation Of Big Data Analytics", Solving Big Data Problems Hamr-Eti.Com Rcollier@Etinternational.Com 302.

[19] B. CliordNeuman, "Proxy-Based Authorization and Accounting for Distributed Systems", the 13th International Conference on Distributed Computing Systems.

[20] F. Canan, PembeMuhtaroglu and SenizDemir, "Business Model Canvas Perspective on Big Data Applications", 2013 IEEE International Congress on Big Data

[21] Automation of an irrigation system. Available at: http://www. thefreedictionary.com/irrigation+ditch

[22] Agriculture system in Bangladesh. Available at: http://www.bookrags. com/ history/terrace-irrigation-ema-05/

[23] Drip Irrigation system. Available at: http://en.wikipedia.org/wiki/Dripirrigation

[24] South Carolina Irrigation / Irrigation equipment. Available at: http://www. clemson.edu/irrig/Equip/Trav.htm 
[25] Dr. B.A.A. Mustafi, Dr. Md. Rafiqul Islam: Development of agricultural politics in Bangladesh. Available at: http://www.ipipotash.org/udocs/ Development-of-agricultural-policies-in-Bangladesh-MAA-Mustafi.pdf

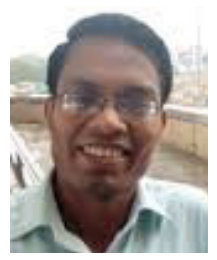

Vijender Kumar Solanki received the Master in Computer Application and Master in Engineering degree (Computer Science \& Engineering) from Maharishi Dayanand University, Rohtak, Haryana, India.(2004 \& 2007). He is pursuing Ph.D. (Computer Science \& Engineering) from Anna University, Chennai, Tamilnadu, India. His primary research interests are in Network Security, Smart Cities and Big Data. He is reviewer of IEEE, Springer \& Elsevier conferences and many International journals. He was the Guest Editor of IJRSDA, Spl Issue on "RICE". He has delivered many Lectures in FDP, Workshop and conferences. He can be contacted at spesinfo@yahoo.com

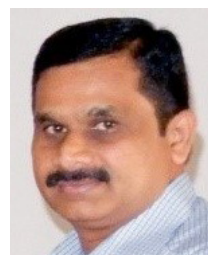

M. Venkaesan is professor in KSRIET, Department of computer science and engineering. He is M.E \& Phd in computer science engineering. His area of research is WSN, Security, Big Data and Smart city. He is having more than decade experience in teaching and research. He is affiliated and approved supervisor with Anna university Chennai. $\mathrm{He}$ is reviewer of numerous high indexed journals. He has conducted many FDP, seminar and conferences successful with high attendances of delegates from in and around country. he can be contact at venkatesh.muthusamy@gmail.com

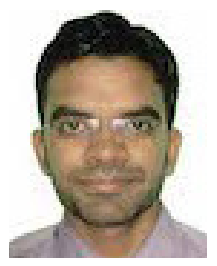

Somesh Katiyar born on Dec 1994, Lucknow India. Received B. Tech degree in Electrical \& Electronics from Chandigarh Group of College, PTU Punjab - India in 2015. His research interest lies in sensor, microcontrollers, machine learning, smart cities , Internet of Things. E-mail : someshkatiyar99@gmail.com 